\title{
PESTICIDE APPLICATION AND FOOD SAFETY ISSUE IN NEPAL
}

\author{
P. Koirala ${ }^{1}$, S. Dhakal ${ }^{2}$ and A. S. Tamrakar ${ }^{3}$
}

\begin{abstract}
:
It has been increasing pest population including weeds, invasive species, insects and insect vectors and plant diseases, which lead to increase pesticides on crop production. Some of the pesticides also contribute to global warming and the depletion of the ozone layer. Pesticides are the potential health hazards which have drawn attention to everyone. The current practice adopted in pesticides control in Nepal appears not enough in line with food safety. This has created a promising threat in food safety and human health. In turn, global warming is also likely to increase pesticide use and degrade food safety situation. Necessary measures should be adopted to curb upcoming alarming situation in food safety.
\end{abstract}

Key words: food safety, global warming, pesticides, Nepal

\section{INTRODUCTION}

Food is synthesis of soil, sunlight and rain (Miller 2004). Current estimate of warming in climate indicates an increase in global mean of annual temperature by $1 \mathrm{C}$ by 2025 and $3 \mathrm{C}$ by the end of next century. Such increases in temperature have a number of implications in temperature-dependent pests (Palikhe 2007). Climate and weather can substantially help the development and distribution of insect pests. Pests and diseases are predicated to spread much further to take advantage of global warming (Cammel 1991). The assessment on investigation of the relationship between pesticide use and warm climate for crops revealed that pesticide requires relatively higher amount than before (Reynolds 1997). Pesticide use is projected to increase for most crops and there is increased need for pesticide application on corm is generally in the range of $10-20 \%$, on potatoes $5015 \%$ and soybean and cotton $2-5 \%$ (Brussel 2006). Flowering pattern, breeding behavior and the timing of migration will be changing. The distribution of plants, insects, animals and even soil bacteria will be shifting rapidly for every $1 \mathrm{C}$ increase in temperature (Lohani 2007).

Global warming which is a gradual rising of Earth's temperature, is different from disaster lime earthquakes, volcanoes eruptions etc representing a scale of threat greater than anything humans have faced in recent history (Bailey 2008). Global warming allows pest migration or population expansion that may adversely affect agricultural productivity, profitability and possibly even viability and safety of food products (Ghimire 2007). Use of pesticide in agriculture has created four fold problems through tropic levels: health related problems, environmental problems, yield loss due to non-target pesticide application resulting in pesticide induced pests resurgence and finally financial burden to the farmer.

There is no comprehensive study has been made so far to know the relationship between use of pesticides and global warming in Nepalese context. Therefore, this study aims to know the current practices regarding the pesticide usage and ultimately aware people about the increasing use of pesticides due to global warming.

\footnotetext{
1, Department of Food Technology and Quality Control, Nepal, pramodkoirala2002@yahoo.com

2 Department of Food Technology and Quality Control, Nepal

3 Tribhuwan University, Kathmandu Nepal
} 


\section{STATUS OF PESTICIDES APPLICATION}

Nepal imports pesticides from six different countries with local production in scant quantity. Fifty-five certified importers are involved in marketing of seventy-three registered common pesticides in three hundred and forty two trade names. The total number of pesticides registered in the country is seventy-three. Among the total registered pesticides, insecticides are major and a total of thirty-nine different insecticides are registered followed by fungicides which is eighteen. Fourteen types of pesticides are banned for normal use by Government of Nepal (Koirala 2009). The study carried out in Department of Food Technology and Quality Control during 1995-2007 for the analysis of 1034 food products, 12.1 percent samples were found contaminated with pesticides (Koirala ${ }^{a}$ 2008). Malathion and BHC were two major pesticides that contaminated in food products (Fig 1)

Figure 1: Pesticides in Food (Koirala, 2008)

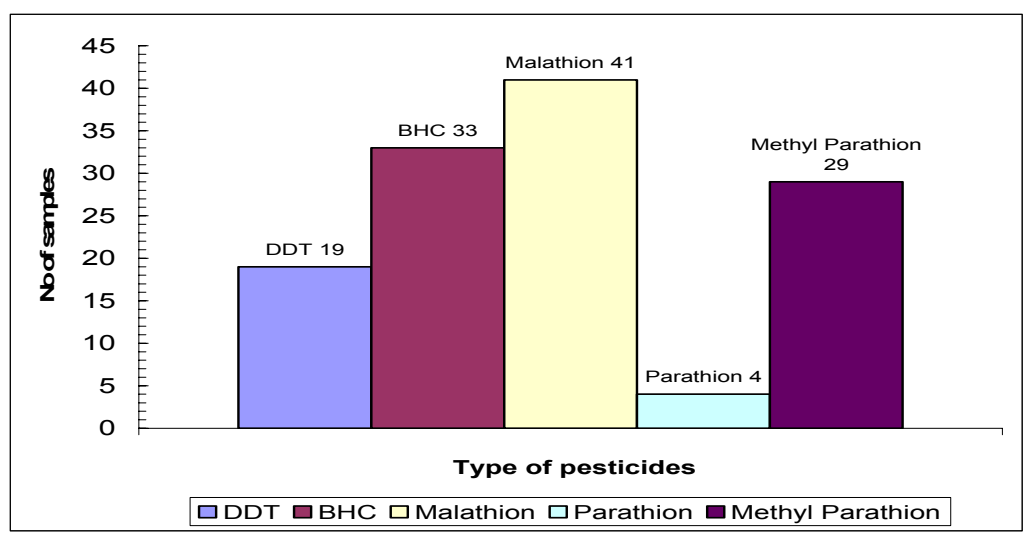

\section{STATE REGULATORY FRAMEWORK AND ORGANIZATIONS}

Pesticide regulation has established guidelines on management of pesticides in Nepal. Pesticide management involves the regulatory control, proper handling, supply, transport, storage, application, use, waste management and disposal of obsolete pesticide in order to minimize adverse environmental effect and human exposure.

The Pesticide Act, 1991 and the pesticide Regulations, 1993 came into effect from 16 July 1994. It covers basic handling techniques of pesticides. The importers wishing to market and sell pesticides shall have to submit an application dealing with the use of pesticides, toxicity, the correct use of pesticides for agriculture safety and human health hazard. No pesticide can be imported into the country without seeking prior Government approval (Pesticide Act 1991).

Food Act, 1967 and Food Regulations 1970 have proposed Maximum Residue Limits (MRLs) for pesticides in food products. But the maximum residue limit has been fixed only for cereals, pulses and their products, processed water and infant food. No MRLs has been fixed for tea. Department of Food Technology \& Quality Control (DFTQC) constantly monitors pesticide residue level in only in those food products where standard has been laid down (Koirala ${ }^{a}$ b 2007).

In order to investigate the level of pesticide in food, laboratory analysis is necessary. In Nepal, the existing pesticide testing facilities are limited to very few organizations. DFTQC , 
Nepal Agriculture Research Council (NARC) and the other two-accreditated private sector laboratory carry out the analysis (Koirala $\left.{ }^{\mathrm{a}} 2008\right)$.

The pesticides to be imported, distributed, traded and used should not possess threat to health and the environment. Large persistent chemical pesticides have been banned for agriculture and public health from April 2001 and other hazardous pesticides have been phased out from the use since April 2001. At present, prohibition on the use of quinalphos, ethion, monocrotophos and phorate in the tea field has already been campaigned and implemented from May 2005. Integrated Pest Management (IPM) approach has been widely accepted as the alternative to pesticide application. Government of Nepal has now phasing out toxic pesticides and application or use of the newer and safer pesticides has been prescribed. Government program at field level is regularly providing training programs on pesticides handling techniques to the farmers.

\section{PESTICIDE ISSUES IN FOOD SAFETY}

Pesticides are the potential health hazards which have drawn attention to food quality control agencies, certification bodies, international community and trading partners. Due to the lack of regular monitoring of pesticides at the field level, the export of tea, honey and other food commodities are adversely affected in the recent years.

Pesticides analysis facility is limited in Nepal. Only few institutions are involving in it and the data available are not sufficient. The laboratories require sophisticated equipments to carry out the residue analysis. Laboratories require reference standard, valid analytical method and are one of the tough jobs. No organized national survey has so far been conducted periodically. Therefore, a valid comparison on use pattern of pesticides cannot be made. The gap between the availability of manpower and other resources requirement is very high which demands the infrastructure support to government as well as to private sector. Similarly, exchange visits, training and other supports by the donor agencies are necessary in order to improve the situation.

The country like Nepal has export potentials for agriculture and processed products. This is not possible unless and until the country doesn't have safe food production. As Nepal has already become a member of WTO, export opportunity can be utilized. It will generate employment and earning to the local people.

Being a member of WTO, Nepal must comply with the SPS requirements. Considering the present pace of implementation, it needs to be done a lot to attain the goal with appropriate harmonization of standards, rules/regulations, guidelines as well as mechanism of inspection and certification of import/export food commodities. In the emerging scenario, there is a need to have MRA at the regional and international level. Risk assessment program should be carried out whenever necessary.

There is no coordinating team for research work on pesticides at field level for the recommendation of appropriate pesticides on crop production. Training / workshop about the use and safety of pesticide should be provided to farmers, retailers and distributors in regular basis. 


\section{CONCLUSION AND RECOMMENDATION}

Global warming will result in an increase in risks of pathogens and chemicals from agriculture to human health. It will fuel increased use of pesticides and biocides as farming practices intensify. The pesticide risk can be reduced from its injudicious use by using IPM approach, and organic manure including vermi-compost, bio fertilizers and pesticides and organic farming. Pesticide Act, 1991 and Pesticide Regulations, 1993 should be effectively implemented. On the other hand, there is an urgent need to establish a national pesticide residue monitoring programme. Likewise, periodic assessment of pesticides and its level of use or limits should be studied for consumers' safety. MRLs of pesticides should be established for vegetables, fruits, and other food grains in accordance with Codex. Introduction of Good Agricultural Practice in the country will help to reduce pesticide risk on food products which will decrease on the pesticide consumption ultimately conserves food safety.

\section{REFERENCES}

Bailey, D., 2008. Climate change impacts on the United States, National Assessment Synthesis Team, US Global Change Research Program, David Suzuki Foundation, Canada.

Bursell, E., 2006. Environmental aspects: temperature. In the physiology of Insects Ed. M Rocketstein vol II pp 283-321, New York: Academia Press.

Cammell, M. E. and Knight J. D., 1991. Effects of climate change on insect defoliator population processes in Canada's boreal forests: some plausible scenarios Water Air Soil Pollut. 82 445-54.

Ghimire, N.P., 2007. Impact of agriculture aggravation on ecology. The Journal of Agriculture and Environment. 8:106-114.

Koirala, P., N.R Dahal, J.P. Lama and U.K. Bhattarai, 2008. An Assessment of Pesticide in Nepalese Tea. JFSTN 4:31-32.

Koirala, P. and A.S. Tamrakar, 2008. Analytical Capability on Pesticide Residue Analysis in Food in Nepal. Abstract published in proceeding of 5th National Seminar organized by Nepal Academy of Science and Technology, Nov 10-12, Kathmandu Nepal.

Koirala, P., N.R. Dahal, S. Dahal, M.R. Bhandari and J.P. Lama, 2008. Pests Ubiquitous and Use of Pesticides in Vegetables in Eastern Region of Nepal. Food Research Bulletin, Kathmandu Nepal

Koirala, P., S. Khadka, S. Dhakal and J.P. Lama, 2007. Tea pests and Pesticides used in Tea in Nepal. Journal of Food Science and Technology (JFSTN). 3:11-15 Nepal.

Koirala, P., D.B. Khadka and A.N. Mishra, 2007. Pesticides Residues as Environmental Contaminants in Foods in Nepal. The Journal of Agriculture and Environment. 8:96-100.

Lohani, S.N., 2007. Climate change in Nepal: Shall we wait until bitter consequences?. The Journal of Agriculture and Environment. 8:38-45.

Miller, G.T., 2004. Sustaining the Earth, 6th edition. Thompson Learning, Inc. California. Pages 211216.

Palikhe, B.R., 2007. Relationship between pesticide use and climate change for crops. The Journal of Agriculture and Environment. 8:83-91.

Reynolds, J.D., 1997. International pesticide trade: Is there any hope for the effective regulation of controlled substances? Florida State University. Journal of Land Use \& Environmental Law. Volume 131. 